\title{
MULHERES NEGRAS E CONSTRUÇÃO DE SENTIDOS DE IDENTIDADE NA TRANSIÇÃO CAPILAR
}

\author{
MUJERES NEGRAS Y CONSTRUCCIÓN DE SIGNIFICADOS \\ DE IDENTIDAD EN LA TRANSICIÓN CAPILAR \\ BLACK WOMEN AND CONSTRUCTION OF MEANINGS \\ OF IDENTITY IN HAIR TRANSITION
}

\section{Cláu dia Lanyelle Revorêdo de Amorim¹, Renata Lira dos Santos Aléssio ${ }^{1}$ e Lassana Danfá ${ }^{1}$}

${ }^{1}$ Universidade Federal de Pernambuco, Recife/PE, Brasil

\begin{abstract}
RESUMO: Transição capilar é o processo de abdicação de alisamentos químicos ou físicos dos cabelos, reassumindo suas texturas naturais. A presente pesquisa, de natureza qualitativa, visou a investigar a construção dos sentidos de identidade em mulheres negras que passaram pela transição capilar. Participaram do estudo 12 mulheres negras com idades compreendidas entre 18 e 34 anos. Para a coleta de dados foram utilizadas entrevistas semiestruturadas que foram analisadas através da análise de posicionamento. A transição capilar mudou a forma de posicionamento em relação a si, ao cabelo, à sociedade e à construção da autoimagem. Além de elucidar o processo de reafirmação identitária das interlocutoras, o estudo fomenta a discussão do racismo na sociedade brasileira, ao tratar da desvalorização da estética negra e, por conseguinte, do enaltecimento da branquitude.

PALAVRAS-CHAVE: Mulheres negras; Identidade; Transição capilar; Racismo.
\end{abstract}

ABSTRACT: Hair transition is the process of abdicating chemical or physical hair straightening, resuming its natural textures. This qualitative research aimed at investigating the construction of the meanings of identity in black women who went through the hair transition. Twelve black women between the ages of 18 and 34 participated in the study. For the data collection, semi-structured interviews were used and analyzed through the positioning analysis. Hair transition has changed the way of positioning towards itself, hair, society and the construction of self-image. In addition to elucidating the identity affirmation process of the interviewees, the study instigates the discussion of racism in Brazilian society, by dealing with the devaluation of black aesthetics and, therefore, the praise of whiteness. KEYWORDS: Black women; Identity; Hair transition; Racism.

RESUMEN: La transición capilar es el proceso de abdicar del alisado químico o físico del cabello, retomando sus texturas naturales. La presente investigación, de carácter cualitativo, tuvo como objetivo investigar la construcción de los significados de la identidad en mujeres negras que atravesaron la transición capilar. Participaron del estudio doce mujeres negras de entre 18 y 34 años. Para la recolección de datos se utilizaron entrevistas semiestructuradas, las cuales fueron analizadas mediante análisis de posicionamiento. La transición capilar cambió la forma de posicionamiento en relación con una misma, el cabello, la sociedad y la construcción de la autoimagen. Además de dilucidar el proceso de afirmación identitaria de las interlocutoras, el estudio fomenta la discusión del racismo en la sociedad brasileña, al abordar la devaluación de la estética negra y, por tanto, el elogio de la blancura.

PALABRAS CLAVE: Mujeres negras; Identidad: Transición capilar; Racismo. 


\section{Introdução}

A presente pesquisa investigou o processo de construção de sentidos de identidade em mulheres negras que passaram por transição capilar. Observa-se que a estética negra presente na sociedade brasileira tem sido alvo da ideologia do branqueamento racial, cujas principais características são a tentativa de "aniquilamento, sem sucesso, da raça e de destruição da identidade e cultura negra (Nascimento, 2016). A propósito, na década de 80, Jurandir Freire Costa (1984, p. 104) afirmou que:

Ser negro é ser violentado de forma constante, contínua e cruel, sem pausa ou repouso, por uma dupla injunção: a de encarnar o corpo e os ideais de Ego do sujeito branco e de recusar, negar e anular a presença do corpo negro [...] a violência racista do branco é exercida, antes de mais nada, pela impiedosa tendência a destruir a identidade do sujeito negro.

Estamos falando de racismo como fenômeno assente nas instituições e pensamento social, que estrutura e organiza as relações intergrupais, extrapolando os traços individuais de personalidade, e atuando, portanto, no nível político-ideológico. Compreende-se também como racismo a negação das diferenças não apenas em termos raciais, mas também em termos de sucessos econômicos (Camino, Tavares, Torres, Estramiana, \& Garrido, 2014). Relegando aos negros, segundo os autores, valores ligados a aspectos físicos, por exemplo, exotismo e espetacularização, insucesso e subdesenvolvimento, ao passo que aos brancos são reservados valores intelectuais vinculados ao topo da pirâmide social e progresso "civilizacional”.

O racismo atua assim na exaltação de diferenças positivas para os brancos e realce de diferenças negativas para negros. Um tipo de negação da diferença chamado por Achille Mbembe (2018a) de alterocídio, que consiste na relação em que o outro é objetificado, tido como dessemelhante a si mesmo, ameaçador e um estranho permanente, podendo culminar com a destruição de todas as suas formas de referência e identidade cultural. Essas formas de manifestação do racismo tornam importante a reflexão sobre os diferentes tipos de configurações de cabelos na sociedade brasileira, que são menosprezados em prol de um único modelo, neste caso, o cabelo liso. Em seu tex to sobre a necropolítica, Mbembe (2018b) compreende a morte para além da destruição e aniquilamento do ser, operando em forma de luxuosidade, na medida em que há uma escolha e programação de quem deve viver ou morrer. Vivem os privilegiados e aos desprivilegiados, os negros, por exemplo, restalhes uma morte programada. Portanto, para este grupo social, atua concomitantemente a necrose e apoptose. Mbembe salienta ainda, que a imagem estereotipada do negro nos dias atuais favorece tanto quanto no passado a execução de práticas da desumanização e industrialização da morte, e, por conseguinte, a necropolítica.

O racismo pensado do ponto de vista das estruturas sociais é sustentado pelos mecanismos de influência social, em que estão inseridas as dinâmicas intrafamiliares, sistemas educacionais, estruturas políticas e organizacionais e influências midiáticas (Vala, 2013). Nesse sentido, as redes de solidariedade e de acolhimento familiar estão imersas em um conjunto social marcado pelo racismo, que se manifesta através de relações hostis dirigidas à estética e corporeidade negra. Por exemplo, a depreciação do cabelo cacheado ou "black". 
A espessura dos lábios, o formato do nariz e a textura do cabelo são consideradas características relevantes na classificação do ser "belo" na sociedade ocidental. Dessa forma, quem possui nariz afilado, pele branca, lábios finos e cabelos lisos é considerada/o bela/o em contraposição a quem possui cabelos crespos, lábios grossos e nariz largo, ou seja, características reconhecidas como negras e enquadradas na categoria de não belas (Malachias, 2007). Ressalta-se que a escolha dessas categorias como elementos fundamentais da classificação racial, por exemplo, a exaltação do nariz em detrimento da orelha, não é neutra nem natural, e sim, reflexo de sistemas ideológicos, que necessitam ser levados em conta. O que significa dizer que a eleição de determinados traços fenotípicos é produzida socialmente. A partir de Schucman (2014), afirmamos que a noção da branquitude ${ }^{1}$ não ocorre por meio das características genéticas, e sim através da definição sistemática e estrutural de lugares de privilégio ocupados pelos sujeitos fenotipicamente brancos, historicamente produzidos e naturalizados.

De acordo com Figueiredo $(2002)^{2}$, desde muito cedo as mulheres são socializadas para alisar os cabelos, procedimento muitas vezes imposto pela família, pois com o cabelo liso, os processos desgastantes, citados em Gomes (2002) para pentear e deixar o cabelo o mais "comportado" possível, passam a ser desnecessários. Esse alisamento, como referido por Mattos (2015), não se faz apenas com os produtos químicos, como a amônia, mas também com pentes quentes, e inclusive, com ferro de passar roupa. Ao alisarem os cabelos, essas meninas veem a possibilidade de estarem com as madeixas sempre desembaraçadas e não precisarem mais sofrer com os "puxões" dos pentes (Gomes, 2002). Nota-se, dessa forma, a relação que se estabelece entre cabelo liso e "praticidade" e entre cabelo crespo e o "trabalho" no cuidar. Essas relações refletem assim uma estética racista que vem sendo denunciada e problematizada pelo feminismo negro.

A separação do feminismo em branco e negro foi de grande relevância para a discussão das particularidades da mulher negra em relação à branca. De acordo com bell hooks (2015), antes da existência do feminismo negro, as mulheres brancas eram quem dominava o feminismo sem se preocupar se a sua experiência pessoal conseguia abarcar as experiências do coletivo, e ainda, sem o cuidado de analisar se a sua perspectiva manifestava preconceito de raça ou classe. A autora traz ainda que o feminismo contemporâneo tem a ideia de que "todas as mulheres são oprimidas", sugerindo, dessa forma, que todas as mulheres compartilham da mesma experiência, porém, não levam em conta aspectos relevantes como raça, orientação sexual, classe ou religião, que se unem ao fato de ser mulher, diferenciando as opressões sofridas. A especificação de um feminismo com ênfase na raça é de suma importância para abarcar de forma contextualizada as opressões sofridas, a começar pela estética negra, que é vista, como já mencionado, como inferior à estética branca eurocêntrica, a considerada bela.

Essa adjetivação do feminismo foi extremamente importante, pois mesmo ativas no movimento feminista contemporâneo desde o seu início, as mulheres negras não se tornaram destaque no movimento. Porém, essa diferenciação não implica dizer que houve uma trivialização da ideia de sororidade feminina, apenas buscou-se afirmar que a luta conjunta só poderá ser feita com a confrontação das maneiras pelas quais as mulheres - por meio de diversos fatores, tais como raça e classe, podem oprimir outras mulheres (Hooks, 2018). Ao se diferenciar do feminismo branco, as mulheres negras começam a lutar não mais só contra o sexismo, mas sim contra o sexismo e contra o racismo, que é extremamente corporificado. 
Na contemporaneidade, é notório o surgimento de uma diversidade estética mais contemplativa, com uma maior representatividade de cabelos crespos e naturais, mas nem por isso, pode-se considerar como um novo tempo menos preconceituoso e racista (Mattos, 2015). Essa maior insurgência de cabelos crespos é dada, também, por pessoas que decidem abandonar os procedimentos estéticos capilares. Esse processo é conhecido como transição capilar, e é caracterizado como a passagem do cabelo alisado, a partir de tratamentos químicos ou térmicos, para a sua textura natural enrolada ou crespa (Mattos, 2015). No decorrer desse processo, que pode ser longo, o cabelo fica com duas texturas, a raiz, que está crescendo, natural, e o comprimento, alisado. Para minimizar a diferença são utilizadas diversas técnicas com diferentes texturizações e finalizações, como a fitagem, processo em que se divide o cabelo em "fitas" com os dedos. Ou pode ser realizado o Big chop, expressão em inglês que significa o "grande corte", ou seja, a retirada de toda a parte alisada do cabelo de uma só vez.

Para as iniciantes no processo, há diversas marcas que estão se especializando em produtos, não só para os cabelos já naturais, como também para os cabelos que estão em fase de transição. Para o aprimoramento das suas vendas e dos seus produtos, algumas


embaixadoras. Todas essas mulheres passaram por transição capilar e resolveram compartilhar o processo e como fazem para cuidar dos cabelos durante e após o processo de transição ter sido concluído. Essas blogueiras serviram de inspiração do ponto de vista estético para algumas meninas e mulheres, que, por conseguinte, optaram pela transição.

É importante realçar que não necessariamente a questão estética abordada pelas blogueiras vem acompanhada de debate racial, ou seja, de discussões sobre racismo e como ele agiu e permanece agindo sobre a população negra. O cabelo crespo ou cacheado entrou no mercado da moda, podendo ser um meio de servir aos interesses dos capitais financeiros. Dessa maneira, como afirmado por Menezes (2013), o racismo pode ser útil ao capitalismo até certo ponto, pois o sistema tem condições de incorporar algumas demandas do movimento negro, desde que não interfira no seu processo de acumulação de capital. Apesar do caráter mercantil dos blogs estimuladores dos cabelos negros, é explícita a importância na promoção da estética negra.

A transição capilar é uma experiência majoritariamente negra feminina, pois o cabelo crespo é tido como inferior ao cabelo liso, que é o reconhecido como "bom", ao passo que o primeiro é comumente denominado como "ruim". A partir desse estereótipo de cabelo bom ou ruim, muitas mulheres, na tentativa de terem a estrutura do cabelo mais próxima do dito cabelo "bom", aderem às químicas, e como já afirmado por Quintão ${ }^{5}$ (2013), o objetivo é que esse alisamento permita que o cabelo pareça o mais natural possível, como se fizesse parte do próprio fenótipo de quem adere a esse tipo de modificação capilar.

Em conformidade com Soares ${ }^{6}$ (2018), a transição capilar pode ser considerada um empoderamento individual, mas com alcance social. Individual porque há um maior conhecimento de si e da capacidade de mudança pessoal e social, pois ao interagir com o outro a sua mudança pode ser um estímulo para transformação do grupo. O "eu” assume a posição central na construção das narrativas de si, na medida em que serve de epicentro para o diálogo de posições internas e externas. As internas são diferentes posições que os indivíduos ocupam. A de filha, por exemplo. As posições, no nível interno, são constituídas na relação com os interlocutores que ocupam as posições externas, neste caso, família, amigos e escola (Ew, Castro, \& Rocha, 2017). Para esses autores, as narrativas de si 
constituem as organizações de self, que emergem a partir dos envolvimentos desses nas interações sociais e das distintas posições adotadas no diálogo. Por sua vez, Moutinho, Meira e Di Conte (2013) consideram que as narrativas são formas de discurso que assumem papéis importantes na construção dos sentidos que decorrem nas nossas vidas.

As construções de narrativa de si implicam posicionamentos de si face às posições sociais marcadas pelas narrativas sociais dominantes ou mestres, isto é, aquelas que são disponibilizadas, partilhadas socialmente e amplamente aceitas. No nosso estudo, as narrativas mestres colocam a branquitude como a beleza mais "aceitável" e "normal", e a negritude vista de forma negativa e não idealizada. Nesse sentido, os sujeitos assumem determinadas posições, que são prescritas nas práticas sociais e discursivas. A noção de posição assume, assim, uma acepção metafórica do lugar ocupado pelos sujeitos, a partir da determinada inserção moral em detrimento da outra. Ressalta-se que as narrativas de si implicam necessariamente o olhar do outro, uma vez que é na relação com o outro que somos capazes de atribuir as significações boas ou más sobre nós. Salienta-se que as narrativas sociais dominantes não são aceitas sem contestação, tendo em conta os embates ideológicos e normativos com os sujeitos desfavorecidos, podendo impactar na sua reformulação no âmbito das relações sociais (Moutinho et al., 2013).

Dessa forma, percebe-se que é através de um posicionamento de si e do outro que as pessoas conferem sentido a si mesmas, que se interpretam como bonitas ou feias, como alegres ou tristes, como boas ou más. Esse posicionamento permite com que se organize narrativamente, em cada lugar e tempo, os sentidos de si e de identidade (Moutinho et al., 2013).

O processo de construção das narrativas de si é marcado por várias tensões, dentre os quais pontos de viragem, que consistem em transformações marcantes no percurso de vida das pessoas. Esse marco temporal da vida dos sujeitos não acontece de forma linear, uma vez que é um processo marcado por tensões, conflitos, incertezas e crises (Oliveira \& Rego, 2006). Conforme apontam as autoras, os pontos de viragem só são possíveis tendo determinados marcadores disponibilizados pela cultura na qual as narrativas individuais estão imersas, ou seja, existe uma relação de reciprocidade entre as narrativas individuais e os aspectos socioculturais. Os pontos de viragem podem significar a possibilidade de experienciar momentos de transição nas trajetórias de desenvolvimento.

Segundo Tânia Zittoun (2014), a transição consiste em dinâmicas mais ou menos voluntárias em torno das quais as pessoas procuram definir novos modos de agir e compreender o mundo que as circunda. A transição mobiliza novas situações que colocam em questão os modos de fazer e agir de uma pessoa através de dois processos: a ruptura com a forma de vida anterior e a mudança necessária para se adaptar às novas situações, isto é, rompimento de uma determinada rotina. Além dos dois aspectos citados, possíveis transtornos e mal-estar em decorrência dos rompimentos com as situações "normais", mudanças pessoais e importantes modificações psíquicas podem ocorrer em um processo de transição. O que significa dizer que ganhos e perdas são comuns. Dentre os benefícios temos: aquisição de novas competências sociais relacionada à compreensão de normas explícitas e implícitas, isto é, a socialização; novos rearranjos identitários, novas situações implicam negociação de papéis e status da pessoa. Nesse caso, as novas experiências supõem mudanças na autoimagem e na percepção de si. E por último, a construção de significado pessoal da situação, inscrita em uma nova narrativa sobre si. $\mathrm{O}$ que permite a releitura da experiência de si numa perspectiva temporal, mantendo certa constância identitária, articulando passado e um eventual futuro (Zittoun, 2014). 
A transição não ocorre de forma solitária, tendo em vista que segue certas normas ou padrões disponibilizados pela cultura e que orientam as mudanças. No caso do nosso estudo, as políticas afirmativas, movimentos como o Encrespa Geral ${ }^{7}$ que incentivam a beleza negra, através de autoafirmação de cabelo (cacheado ou crespo), podem ser definidos como dispositivos transitórios (Zittoun, 2014) encontrados na sociedade brasileira contemporânea. Esses recursos cumprem uma elevada importância, tendo em vista que são capazes de contribuir para reafirmação dos valores da negritude do ponto de vista estético, identitário e político. Este estudo se propôs, portanto, a investigar a construção dos sentidos de identidades por intermédio de posicionamento de si em mulheres negras que passaram por processo de transição capilar.

\section{Método}

\section{Participantes}

Foram realizadas 12 entrevistas semiestruturadas com mulheres entre 18 e 34 anos entre julho e setembro de 2017 , que passaram pelo processo de transição capilar e que se reconheciam como negras. A tabela 1 apresenta as participantes, suas idades, momento da transição capilar e escolarização.

Tabela 1. Características das participantes do estudo

\begin{tabular}{cccc}
\hline $\begin{array}{c}\text { Nome } \\
\text { Fictício }\end{array}$ & Idade & $\begin{array}{c}\text { Momento da } \\
\text { Transição Capilar }\end{array}$ & Escolarização \\
\hline Fernanda & 20 anos & Fim do Ensino Médio & Graduanda de Fisioterapia \\
\hline Lorena & 23 anos & Início da Graduação & Graduanda de Letras \\
\hline Gabrielle & 23 anos & Ensino Médio & Graduanda de Ciências Contábeis \\
\hline Maira & 20 anos & Fim do Ensino Médio & Graduanda de Psicologia \\
\hline Clarice & 21 anos & Fim do Ensino Médio & Mestranda em Antropologia \\
\hline Carolina & 18 anos & Após a festa de 15 anos & Graduanda de Designer \\
\hline Dara & & Fim do Ensino Médio & Graduanda de Psicologia \\
\hline Laura & 21 anos & Durante a Graduação & Graduanda de Letras \\
\hline Laís & 20 anos & Fim do Ensino Médio & Graduanda de Psicologia \\
\hline Marina & 22 anos & Início do relacionamento & Graduanda de Letras \\
\hline Suzete & 21 anos & $\begin{array}{c}\text { Início da Graduação e } \\
\text { Início de relacionamento }\end{array}$ & Graduanda de Letras \\
\hline Flávia & 34 anos & Durante a Graduação & Graduanda de Letras \\
\hline
\end{tabular}

Fonte: elaboração das autoras 


\section{Instrumento e coleta de dados}

O roteiro de entrevista semiestruturada possuía perguntas que versavam sobre a relação com o cabelo na infância, os motivos do alisamento e da transição capilar, assim como as diferenças entre a relação com o cabelo antes e depois da transição capilar, e se houve alguma alteração na percepção de si em decorrência desse processo. Foi ainda abordada a questão da percepção do racismo.

\section{Análise de dados}

O conteúdo das entrevistas foi analisado inspirado nos estudos de Moutinho e De Conti (2017) com mulheres que passaram por cirurgia bariátrica. As autoras analisaram entrevistas tomando como referência o modelo de análise de narrativa, através da construção de sentidos de identidade e posições de si, em face às narrativas sociais dominantes que emergem e se modificam ao longo da construção das narrativas de si. Dessa forma, o referido procedimento analítico é denominado análise de posicionamento. Para a obtenção de melhores resultados no seu estudo, as autoras desenvolveram categorias, as quais também foram utilizadas na presente investigação, atendendo às seguintes divisões: pequenas histórias, posições, e o espaço-tempo (antes, durante e depois). Faz-se importante ressaltar, ainda, que para a análise das posições foram criados alguns qualificadores, os quais foram agrupados em quatro tipos, em consonância com Moutinho e De Conti (2017), conforme disposto a seguir: conforto, desconforto, controle e descontrole. Os qualificadores formam uma categoria de adjetivação atribuída aos personagens da narrativa. Além dos qualificadores, a narrativa e o enredo foram utilizados como recursos para a análise das posições.

\section{Aspectos éticos}

Todas as participantes receberam esclarecimentos prévios sobre o objetivo do estudo, e aceitando participar, as entrevistas eram agendadas de acordo com a disponibilidade de cada uma, e somente foram realizadas após a assinatura do Termo de Consentimento Livre e Esclarecido. O projeto foi aprovado pelo Comitê de Ética em Pesquisa da Universidade Pernambuco sob protocolo CAEE n. 72115817.1.0000.520. Para preservar o anonimato das mulheres, seus nomes foram mascarados por nomes fictícios.

\section{Resultados e Discussão}

A análise de posicionamento tem como cerne a proposição de posições morais do narrador em relação a si mesmo. As posições foram analisadas a partir de qualificadores no espaço-tempo que, nesse caso, teve a transição capilar como marcador (o antes, o durante, e o depois). 


\section{Período anterior à transição capilar}

Nas narrativas analisadas no espaço-tempo anterior à transição capilar, notou-se a predominância do qualificador de desconforto quando se referiam a si. São qualificadores de desconforto as formas de adjetivação atribuídas a si ou aos outros personagens da narrativa que estejam relacionados a sofrimento, angústia, desprazer, mal-estar e insatisfação com a aparência do cabelo crespo ou cacheado, ao passo que os qualificadores de conforto demonstram prazer, felicidade, bem-estar e satisfação com a aparência relacionada ao cabelo. Embora duas das mulheres tragam em seus discursos adjetivos que podem ser identificados como de bem-estar, todas no decorrer da entrevista trazem esse bem-estar como provisório, como no referido trecho dito por Fernanda:

Da primeira vez que eu fiz minha gente, vocês não têm noção, eu tive que ficar três dias sem lavar o cabelo, quando eu lavava o cabelo, eu fiquei "meu deus, maravilhoso, num sei quê” porque naquele momento era o que eu achava que precisava, entendesse? Só que no início é tranquilo, e depois começa a ser massacrante, você começa a ser refém daquilo, você começa a ser escrava daquela situação e eu fui escrava dessa situação por muito tempo.

Esse conforto inicial está relacionado ao fato de conseguir o cabelo alisado almejado, porém o desconforto surge logo em seguida pela dificuldade em mantêlo, sendo simbolicamente comparado à escravidão, como mencionado por Fernanda. A expressão "escravidão" é bastante significativa nesse contexto, visto que foi um processo vivenciado por pessoas negras em que houve a supressão da sua liberdade, da estética e da sua cultura. Como já exposto por Gomes ${ }^{8}$ (2017), durante séculos de escravidão a barbaridade do regime escravista materializou-se na maneira como o corpo negro era percebido e tratado. A oposição percebida nesses corpos observada na cor da pele e nos outros sinais diacríticos, tais como nariz, boca e cabelo, foram utilizadas como mais uma justificativa para a colonização ocultando as intencionalidades econômicas e políticas. E foi justamente a confrontação dessa estética que, segundo a autora, possibilitou a formação de argumentos que sustentam um padrão de beleza assente na estética eurocêntrica e um padrão de fealdade no que concerne à aparência negra.

A partir disso se faz necessário detalhar as situações nas quais todas as mulheres relataram desconforto com o cabelo no período anterior à transição capilar. Um dos motivos principais diz respeito a não identificação com o cabelo cacheado decorrente da narrativa social que traz os sinais diacríticos da branquitude, neste caso, o cabelo liso, como o ideal estético. Para exemplificar, analisemos agora um fragmento da entrevista de Lorena:

Então eu achava que era normal a pessoa que tinha o cabelo crespo ou cacheado alisar o cabelo. Eu não achava que eu poderia usar o meu cabelo normalmente, sabe? Então era basicamente assim. Então eu não tinha muita... eu não via ele como algo meu, sabe? Eu achava que o meu cabelo era o alisado e não o cabelo era o cacheado.

Nota-se como a narrativa social dominante influencia no posicionamento de Lorena sobre si fazendo com que ela chegasse a acreditar que o cabelo dela não fosse o natural, mas aquele ao qual ela estava sendo imposta. Esse processo psicológico pode ser compreendido a partir de Fernandes e Souza (2016) como uma relação alteritária entre os negros, grupos 
sociais dominados, e os brancos, grupos sociais dominantes, consistindo na atribuição de traços estereotípicos negativos aos primeiros e estereótipos positivos aos segundos. As autoras compreendem ainda essa relação como binarismo identitário, marcado pelas identidades polarizadas, isto é, a negação do ser negro em contraposição com a idealização do ser branco.

Outro exemplo identificado como qualificador de desconforto diz respeito ao sofrimento relatado para pentear os cabelos, como afirmado por Gabrielle: "Meu cabelo para desembaraçar era a pior coisa do mundo, era um sofrimento porque parecia que mainha não queria cuidar do meu cabelo e ela ficava puxando muito véi... dóia a minha cabeça". Infere-se no relato que até a relação de cuidado da mãe com a filha, ou seja, o ato de pentear os cabelos em crianças negras é facilmente confundido com um tormento. A possível falta de informação dos cuidadores responsáveis sobre cuidado com o cabelo cacheado/crespo demonstra a adesão à narrativa social dominante de que o cabelo liso é ideal para mulher.

Além dos qualificadores de conforto e desconforto também foram identificados os de controle e de descontrole. Foi observado que houve preponderância do qualificador de descontrole. O qualificador de controle refere-se a adjetivações que associam ao personagem responsabilidade por suas ações ou tomada de decisões. Inversamente, o de descontrole é percebido através da inexistência dessa responsabilidade pelo personagem (Moutinho \& De Conti, 2017). Percebe-se que nas narrativas analisadas esse descontrole por parte das mulheres estava relacionado tanto pela não escolha em alisar os cabelos, como pode ser visto no relato a seguir:

$\mathrm{Na}$ verdade, não fui eu que decidi alisar, né? O meu cabelo... eu era pequena, e daí eu passei um tempo morando com a minha tia, ela que cuidava, não era mais a minha mãe e ela passou o produto porque ela achou que seria mais fácil de cuidar e tal. (Maira)

Como também pelo impedimento de realizar o mesmo no momento em que queria, só sendo possível algum tempo depois, como exposto por Fernanda "Eu comecei a alisar muito nova, desde... eu acho dos 12/13 anos. Foi muito nova mesmo. Minha mãe bateu na tecla "não, não, não", eu disse "eu quero, eu quero, eu quero" até ela...". Nota-se que as mulheres no período pré-transição capilar não possuíam a autonomia do que fazer com os seus cabelos, estando sempre dependentes de algum cuidador responsável para as deixarem alisar ou para alisarem sem a preocupação de saber se elas o desejavam.

\section{Período durante a transição capilar}

Durante o período da transição capilar, observou-se que seis mulheres continuaram relatando desconforto ao passo que cinco trouxeram adjetivos que foram enquadrados no qualificador de conforto e apenas uma apresentou um discurso ambíguo sobre essa fase. Um exemplo de fala que identifica essa fase como desconfortável é o relatado por Clarice:

Quando começou a brotar as texturas eu não sabia o que fazer. No começo foi um pouco difícil pra mim aceitar... porque sempre é um choque no começo, sabe? Tipo assim... você tem toda uma rotina de ir pra salão, alguém cuidar do seu cabelo pra você, e você dormir e acordar já pronta, tira a touca e sai, né? Assim... todo uma coisa montada pra você só viver, pra você viver tranquila, sabe? 
Já no que diz respeito às mulheres que relataram conforto desde o período de transição notou-se que ele estava ligado à liberdade de poder fazer o que quisessem sem se preocupar com o cabelo ou se fazer refém dele como o exposto por Lorena:

Então eu fui, passei uma semana sem alisar, não sem alisar, sem molhar, molhar ele, lavar, mesmo ele alisado, foi difícil, no início. Mas eu percebi que eu ficava mais à vontade com o cabelo um pouco bagunçado do que alisar ele, sabe? Eu me sentia mais livre.

Diferentemente do observado no período anterior ao início da transição capilar, identifica-se um maior controle percebido das mulheres sobre os cuidados com seus cabelos em todas as narrativas. Controle que se reforça no período pós-transição, acrescido da autoestima elevada.

\section{Período posterior à transição capilar}

No período posterior à transição capilar todas as mulheres se posicionaram de maneira positiva na construção de narrativas sobre si, fazendo com que o qualificador de conforto fosse predominante. Compreendeu-se que esse resultado se deve ao reconhecimento identitário materializado no seu cabelo, como relatado por Clarice: " $\hat{E}$ uma relação de...um sentimento de, digamos assim, identidade, né? É você se reconhecer no seu cabelo e, consequentemente, na valorização da estética negra”. Neville e Cross (2016) chamam atenção para ausência de trabalhos mostrando eventos críticos que promoveram mudança de percepção e reinterpretação sobre identidade negra. A transição capilar parece ser um desses eventos, pois foi considerada um ponto de viragem na vida de onze das mulheres entrevistadas, excetuando-se por uma. Destacamos o relato de Carolina:

E eu digo que eu realmente mudei de vida quando eu passei pela transição. Eu tô tentando não chorar, mas... é, eu digo que eu realmente mudei de vida quando eu passei pela transição porque foi outra pessoa. Quem me conheceu antes é... sabe que eu não sou a mesma pessoa, sabe? Tanto por fora, por dentro, de todas as formas eu não sou mais a mesma Carolina e tipo eu digo para quem me perguntar que a transição foi o ponto mais alto da minha vida, que mais me marcou.

A transição capilar aparenta muito mais do que uma mudança estética, mas uma mudança de si e de posicionamento, pois, como já dito por Botezini (2014) $)^{9}$, o cabelo está diretamente intrincado a uma identidade pessoal feminina. Nesse sentido, o corpo é imprescindível no processo da construção da identidade, uma vez que, a identidade deriva em grande medida da relação que estabelecemos com o corpo. É na imagem corporal, cabelo, nariz, boca, por exemplo, onde os sujeitos experienciam a dor, o prazer e o desprazer (Costa, 1984).

A experiência humana é marcada pela existência de um corpo em movimento em uma sociedade, é uma experiência semiótica, temporal e ontologicamente relacional. Marcada por mudanças de posicionamento ao longo da vida, a experiência humana significa entrar em contato com as contradições da cultura e da sociedade na qual se está inserido, forjando novas posições (Zittoun \& Gillespie, 20015). A transição capilar pode ser compreendida como uma transição no sentido proposto por Zittoun (2014), pois proporciona novas formas de pensar e falar sobre si, ao mesmo tempo em que mobiliza novos arranjos sociais e competências sociocognitivas. 
O cabelo também foi personificado, tendo sido descrito como um personagem propulsor do desconforto, tendo em conta que ele gerava perdas e interferia na tomada de várias decisões das mulheres, o que inclui lazer, como entrar na piscina. As entrevistadas travavam uma "guerra" com o cabelo com o intuito de travar o incômodo gerado pelos cabelos crespos e cacheados personificados enquanto um inimigo a ser derrotado. Após a transição capilar, entretanto, o cabelo passa a ser um personagem "companheiro", como mostra o seguinte trecho da fala de Fernanda: "Hoje em dia ele acorda um pouquinho problemático, eu digo ah, cabelo hoje é teu dia, vou deixar tu assim, vou te respeitar um pouquinho. Hoje eu tenho uma relação de muito amor com o meu cabelo", notando-se, dessa forma, que a relação deixou de ser de luta para ser de amor e respeito.

Apesar de centrarmos a nossa discussão no posicionamento das narrativas de si para as mulheres negras entrevistadas, observamos que se posicionaram em relação aos outros personagens da narrativa, nesse caso, a família e os colegas da escola na fase pré-transição e os namorados na fase pré e durante transição. Sobre os membros da família (pai, mãe, irmãos, tias, avós), sete entrevistadas relataram total desconforto desses em relação ao cabelo crespo e cacheado:

Aí toda minha família tem essa coisa do tipo me ver e aí passar a mão no meu cabelo e falar "ah, podia dar uma abaixadinha" ou então... porque o meu cabelo é crespo, ele não é cacheado, cacheado, então tem essa coisa "podia definir um pouco mais os cachos, né?" e isso... tipo por mais que eu tenha todo o conhecimento, que eu sei que isso é uma coisa de identidade, quando eu tô no meu meio familiar eu me sinto enfraquecida. (Dara)

Assim ...dentro de casa eu ouvia todos os dias coisas ruins e meu pai ele até falava assim "minha filha, você tá sem dinheiro? Se você quiser eu pago pra você ir alisar o seu cabelo." (Marina)

O desconforto relatado pelas mulheres entrevistadas se explica pela adesão dos familiares à narrativa social dominante, que valoriza o ideal estético branco-europeu. Por outro lado, embora as entrevistadas não possuam a consciência prematura das respectivas pertenças étnico-raciais, é importante destacar que as atitudes preconceituosas dos outros colegas da escola durante a infância foram relatadas como desconfortáveis, como para Marina: "Ela me chamava de Maria, de Severina, dizia que eu tava parecendo uma empregada, sabe? Mas a gente vai relevando né?”.

$\mathrm{O}$ que decorre do racismo e preconceito antinegro institucionalizado e enraizado no pensamento social brasileiro, capaz de ser ensinado e assimilado pelas crianças desde a tenra idade. Entretanto, diferentemente da família e dos colegas da escola, os namorados aparecem em alguns relatos como incentivadores para o início do processo de transição. $\mathrm{O}$ apoio significativo dos namorados pode favorecer a construção de uma imagem positiva das entrevistadas, uma vez que são pessoas com as quais mantinham um vínculo afetivo-emocional:

Na verdade, teve uma pessoa que foi o meu namorado, né? Que ele falou assim... "mas por que" ele fez a pergunta "por que tu alisa, hein?" Porque eu alisava sempre, sempre, sempre, sempre e ainda não deixava do jeito que eu queria, eu tinha que ficar dando chapinha. Ai ele meio que "Por que tu alisa?" Ai veio aquela "poxa, por que né?" Não é porque eu quero, é porque eu tô... é como se eu tivesse que continuar fazendo aquilo porque se não também não me achava bonita de jeito nenhum. (Maíra) 
Se observarmos os qualificadores de controle e descontrole, percebe-se, portanto, durante a infância e parte da adolescência, que os familiares responsáveis possuíam controle total sobre o cabelo das entrevistadas, ao passo que os amigos da escola (no ensino médio) e os namorados não o possuíam, esses podiam apenas expressar os desconfortos e preconceitos ou estimular a transição capilar, respectivamente. Essas mulheres, quando crianças, estavam envoltas dentro de uma rede de significações (enredamento) que as incitava ao alisamento do cabelo.

Neste sentido, Rossetti-Ferreira, Amorim e Silva (2004) afirmam que, dentro de determinado contexto, simultaneamente, as pessoas são submetidas às características deles e muitas vezes confrontam ou ajustam as possibilidades colocadas. A ascensão à vida adulta possibilitou novas configurações contextuais que podem ter reposicionado as mulheres em um lugar de poder sobre seus próprios corpos que lhes foi negado quando crianças. $\mathrm{Na}$ atualidade, as relações entre pais e filhos/as tendem a ser menos hierarquizadas no momento da transição para a vida adulta (Ponciano \& Féres-Carneiro, 2014). Entretanto, nos países em desenvolvimento, são múltiplas as trajetórias de jovens rumo à autonomia atribuída ao mundo adulto (Juaréz \& Gayet, 2014).

Especificar as trajetórias de construção de identidades para mulheres negras é uma das formas de investigar o variado panorama de transições que podemos observar. Notadamente em um contexto no qual a ascensão à vida adulta não aparece ligado à saída da casa dos pais, mas em uma coabitação que reconhece o estatuto de autonomia de filhos (Kublikowski \& Rodrigues, 2016). Investigar como as mulheres negras negociam os significados de sua identidade através da estética dos cabelos é uma das formas de perscrutar processos desenvolvimentais e afirmações político-identitárias que ocorrem na confluência de múltiplos fatores. Nesse sentido, não se pode considerar o contexto sem refletir sobre as pessoas que dele participam e as interações por elas estabelecidas.

\section{Considerações finais}

Um enredamento de significações levava essas mulheres a alisar os cabelos para se sentirem bonitas e aceitas na sociedade. No entanto, essa rede se modificou ao longo do desenvolvimento e dos diferentes contextos e pessoas envolvidas neles, contribuindo, dessa forma, para uma mudança de posicionamento de si das mulheres negras pesquisadas. A relação que as entrevistadas mantinham com o cabelo e suas implicações deslocam os qualificadores do total desconforto para total conforto após a transição. Assim, as interlocutoras passaram a se sentir mais bonitas e libertas da escravidão, modo pelo qual se referiam ao processo de alisamento, que as acorrentava e as impedia de aproveitar os prazeres da vida em decorrência da preocupação excessiva com o cabelo.

Conforme relataram onze das entrevistadas, mesmo sendo dolorosa, a transição capilar foi uma grande mudança positiva nas suas vidas, podendo ser considerada um ponto de viragem. O que se deve ao fato da transformação na forma como elas se viam e como se posicionavam, não apenas diante de si, mas em relação aos outros e à narrativa social dominante. O cabelo que antes do processo transitório era visto como um mal a ser combatido passa a ser visto com respeito, cuidado e amor. Dessa forma, o presente estudo fornece uma prova empírica para demonstrar a importância da valorização do cabelo crespo e cacheado na construção da identidade positiva da mulher negra na sociedade 
brasileira. Observou-se, ainda, a construção tardia da consciência da cor e outros traços raciais ou negroides das interlocutoras, que tem como consequência direta a construção de uma imagem desfavorável sobre si mesmo e a adesão à ideologia do branqueamento. Por conseguinte, esses fatos desfavorecem a percepção rápida do racismo, nesse caso, decorrente da desvalorização dos cabelos crespos e cacheados. O que pode explicar a atuação direta das cuidadoras e "inércia" das interlocutoras até o processo de transição. Estudos futuros sobre a reafirmação e valorização da estética negra devem levar em conta as possíveis relações entre a afirmação político-identitária demorada da origem étnicoracial ou marcas raciais e adesão aos ideais de beleza resultante do branqueamento racial.

Não obstante, acreditamos ser limite deste estudo a não apreensão do ponto de vista dos familiares, parceiros/as e amigos, isto é, das pessoas que direta ou indiretamente serviram de catalisadores para a ocorrência da transição. Acrescenta-se a isso o fato de as entrevistas não explorarem as diferenças e semelhanças dos relatos das mulheres vinculadas e não vinculadas aos movimentos de empoderamento e reafirmação identitária dos movimentos negros, que lutam em prol da construção da identidade positiva do negro. Aliás, os estudos atuais sobre as questões étnico-raciais têm-se debruçado na construção de uma dimensão profícua da negritude. Nesse sentido, acreditamos que os estudos futuros devem investigar as possíveis relações entre a construção da imagem positiva da Europa e os branco-europeus no Brasil e a consequente supervalorização da branquitude. E do outro lado, a relação entre a edificação da imagem negativa sobre África acrescida da aderência ao imaginário negativo da beleza africana no Brasil e a desvalorização na negritude.

Este trabalho fomenta a discussão sobre o racismo e em como ele influencia a metamorfose do corpo negro, principalmente no cabelo, na autoestima, e consequentemente, no posicionamento de si de mulheres negras. Nossos achados permitem ilustrar que contradizer a exaltação da branquitude e do ideal estético dominante pode resgatar a dimensão positiva da identidade negra. 


\section{Notas}

1 Lia Vainer Schucman pensou a branquitude a partir da sua tese de doutorado intitulada "Entre 'encardido', o 'branco' e o 'branquíssimo': raça, hierarquia e poder na construção da branquitude paulistana”, defendida em 2012. Schucman traz o conceito a partir das suas próprias experiências como mulher da descendência judaica, tendo convivido diariamente com as marcas do racismo antijudaíco e consequentemente as feridas do nazismo. $\mathrm{O}$ contex to em que viveu é também marcado pela intolerância a qualquer espécie de discriminação e preconceito. Acrescenta-se a sua identidade judaica, branquitude, que no contexto brasileiro a coloca na condição da privilegiada e na posição hierárquica de superioridade. Assim, "o fato de o preconceito racial recair sobre a população branca está diretamente relacionado ao fato de os privilégios raciais estarem associados aos brancos. O branco não é apenas favorecido nessa estrutura racializada, mas também produtor ativo dessa estrutura, através de mecanismos mais diretos de discriminação e da produção de um discurso que propaga a democracia racial e o branqueamento" (Schucman, 2014, p. 27).

2 Figueiredo, Â.(2002). Cabelo, cabeleira, cabeluda e descabelada: identidade, consumo e manipulação da aparência entre os negros brasileiros. Proceedings of the XXVI Reunião Anual da Associação Nacional de Pós-Graduação e pesquisa em Ciências Sociais, Caxambu, MG. Recuperado de https://www.anpocs.com/index.php/papers-26-encontro/gt-23/ gt17-14/4475-afigueiredo-cabelo/file

3 Termo brasileiro para designar pessoas que escrevem com frequência em blogs.

4. Termo brasileiro para designar pessoas que postam vídeos com frequência em canais do Toutube.

5 Quintão, A. M. P. (2013). O que ela tem na cabeça?Um estudo sobre o cabelo como performance identitária. Dissertação de Mestrado, Programa de Pós-graduação em Antropologia, Universidade Federal Fluminense, Niterói, RJ. (Não-publicada)

6 Soares, A. M. P. (2018). Cabelo importa: os significados do cabelo crespo/cacheado pra mulheres negras que passaram pela transição capilar. Dissertação de Mestrado, Programa de Pós-graduação em Sociologia, Universidade Federal de Pernambuco, Recife. (Nãopublicada)

7 Evento que celebra a inspiração e valorização do uso do cabelo natural.

8 Gomes, L. L. P. (2017). "Posso tocar no seu cabelo?" Entre o liso e o crespo: transição capilar, uma (re) construção identitária? Dissertação de Mestrado, Programa de Pósgraduação em Antropologia Social. Universidade Federal de Santa Catarina, Florianópolis. (Não-publicada)

9 Botezini, N. A. (2014). Cabelos em transição: um estudo acerca da influência dos cabelos afro como sinal diacrítico e reconhecimento étnico. Proceedings of the $38^{\circ}$ Encontro Anual da Anpocs, Caxambu, MG. Recuperado de https://www.anpocs.org/index.php/ papers-38-encontro/gt-1/gt32-1/9135-cabelos-em-transicao-um-estudo-acerca-dainfluencia-dos-cabelos-afro-como-sinal-diacritico-e-reconhecimento-etnico/file 


\section{Referências}

Camino, L., Tavares, T. L., Torres, A. R. R., Estramiana, J. L. Á., \& Garrido, A. (2014). Repertórios discursivos de estudantes universitários: sobre cotas raciais nas universidades públicas brasileiras. Psicologia \& Sociedade, 26(nspe.3), 117-128. Recuperado de https://dialnet.unirioja.es/servlet/articulo? codigo $=4808618$

Costa, J. F. (1984). Violência e psicanálise. Rio de Janeiro: Graal.

Ew, R. A. S., Castro, T. G., \& Rocha, K. B. (2017). Dialogicidade e contradições nas narrativas de si: estudo de casos múltiplos com adolescentes. Athenea Digital. Revista de pensamiento e investigación social, 17(3), 29-52. https://doi.org/10.5565/rev/athenea.1536

Fernandes, V. B. \& Souza, M. C. C. C. (2016). Identidade Negra entre exclusão e liberdade. Revista do Instituto de Estudos Brasileiros, 63, 103-120. https://doi.org/10.11606/issn.2316-901X. v0i63p103-120

Gomes, N. L. (2002). Trajetórias escolares, corpo negro e cabelo crespo: reprodução de estereótipos ou ressignificação cultural? Revista Brasileira de Educação, 21, 40-51. https://doi. org/10.1590/S1413-24782002000300004

hooks, b. (2015). Mulheres negras: moldando a teoria feminista. Revista Brasileira de Ciência Política, 16, 193-210. https://doi.org/10.1590/0103-335220151608

hooks, b. (2018). O feminismo é para todo mundo: políticas arrebatadoras. Rio de Janeiro: Rosas dos Tempos.

Juárez, F. \& Gayet, C. (2014). Transiciones a la Vida Adulta en Países en Desarrollo. Annual Review of Sociology, 40(1), S-1-S-18. https://doi.org/10.1146/annurev-soc-071312-145709

Kublikowski, I. \& Rodrigues, C. M. (2016). "Kangaroo generations": New contexts, new experiences. Estudos de Psicologia (Campinas), 33(3), 535-542. https://doi.org/10.1590/1982$\underline{02752016000300016}$

Malachias, R. (2007). Cabelo bom. Cabelo ruim (Vol. 4). São Paulo: Nove \& Dez Criação e Arte.

Mattos, I. G. (2015). Estética afro-diaspórica e o empoderamento crespo. Pontos de Interrogação, 5(2), 37-53. http://doi.org/10.30620/p.i..v5i2

Mbembe, A. (2018a). Crítica da razão negra. São Paulo: n-1 Edições.

Mbembe, A. (2018b). Necropolitica. São Paulo: n-1 Edições.

Menezes, F. C. (2013). Repensando a Funcionalidade do Racismo para o Capitalismo no Brasil Contemporâneo. Libertas, 13(1), 9-72. https://doi.org/10.34019/1980-8518.2013.v13.18255

Moutinho, K. \& De Conti, L. (2017). Análise narrativa, construção de sentidos e identidade. Psicologia: Teoria e Pesquisa, 32(2), 1-8. https://doi.org/10.15900102-3772e322213

Moutinho, K., Meira, L., \& De Conti, L. (2013). Desenvolvimento e construção narrativa de sentidos de identidade. In K. Moutinho, P. Villanchan-Lyra, \& A. Santa-Clara (Eds.), Novas tendências em Psicologia do Desenvolvimento: teoria, pesquisa e intervenção (pp. 133-158). Recife: Editora Universitária UFPE.

Nascimento, A. (2016). O genocídio do negro brasileiro: processo de um racismo mascarado. São Paulo: Perspectiva.

Neville, H. A. \& Cross, W. E. (2016). Racial awakening: Epiphanies and encounters in Black racial identity. Cultural Diversity and Ethnic Minority Psychology, 23(1), 102-108. https://doi. org/10.1037/cdp0000105

Oliveira, M. K. \& Rego, T. C. (2006). Desenvolvimento psicológico e constituição de subjetividades: ciclos de vida, narrativas autobiográficas e tensões da contemporaneidade. Pro-Posições, 17(2), 119-138. Recuperado de https://periodicos.sbu.unicamp.br/ojs/index.php/proposic/ article/view/8643631 
Ponciano, E. L. T. \& Féres-Carneiro, T. (2014). Relação Pais-Filhos na Transição para a Vida Adulta, Autonomia e Relativização da Hierarquia. Psicologia: Reflexão e Crítica, 27(2), 388397. https://doi.org/10.1590/1678-7153.201427220

Rossetti-Ferreira, M. C., Amorim, K. S., \& Silva, A. P. S. (2004). Rede de significações: alguns conceitos básicos. In M. C. Rossetti-Ferreira, K. S. Amorim, A. P. S. Silva, \& A. M. A. Carvalho (Eds.), Rede de significações e o estudo do desenvolvimento humano (pp. 23-33). Porto Alegre: Artmed.

Schucman, L. V. (2014). Sim, nós somos racistas: estudo psicossocial da branquitude paulistana. Psicologia \& Sociedade, 26(1), 83-94. https://doi.org/10.1590/S0102-71822014000100010

Vala, J. (2013). Racisms: Social representations, racial prejudice and normative pressures. Papers on Social Representations, 22(1), 6-1.

Zittoun, T. (2014). Transitions as dynamic processes - A commentary. Learning, Culture and Social Interaction, 3(3), 232-236. https://doi.org/10.1016/j.lcsi.2014.02.010

Zittoun, T. \& Gillespie, A. (2015). Internalization: How culture becomes mind. Culture \& Psychology, 21(4), 477-491. https://doi.org/10.1177/1354067X15615809

CLÁUDIA LANYELLE REVORÊDO DE AMORIM

https://orcid.org/OOOO-0001-7938-9618

Graduada em Psicologia pela Universidade Federal de Pernambuco.

Endereço: Av. Acadêmico Hélio Ramos, s/n - Cidade Universitária - Recife, PE. CEP

50670-901

E-mail: claudialanyelle25@gmail.com

RENATA LIRA DOS SANTOS ALÉSSIO

http://orcid.org/0000-0001-8548-2771

Professora Adjunta do Departamento de Psicologia da UFPE. Professora do Programa de Pós-Graduação em Psicologia da Universidade Federal de Pernambuco, Recife.

E-mail: renatalir@gmail.com

\section{LASSANA DANFÁ}

https://orcid.org/O000-0002-9598-609X

Psicólogo, Doutor em Psicologia pela Universidade Federal de Pernambuco, Recife.

E-mail: delassanadanfa@,hotmail.com 


\begin{tabular}{|c|c|}
\hline Histórico & $\begin{array}{l}\text { Submissão: 05/6/2019 } \\
\text { Revisão: 16/8/2020 } \\
\text { Aceite: } 16 / 9 / 2020\end{array}$ \\
\hline Contribuição dos autores & $\begin{array}{l}\text { Concepção: CLRA } \\
\text { Coleta de dados: CLRA } \\
\text { Análise de dados: CLRA; LD; RLSA } \\
\text { Elaboração do manuscrito: CLRA; RLSA; LD } \\
\text { Revisões críticas de conteúdo intelectual } \\
\text { importante: CLRA; RLSA; LD } \\
\text { Aprovação final do manuscrito: CLRA;RLSA; LD }\end{array}$ \\
\hline Consentimento de uso de imagem & Não se aplica \\
\hline Aprovação, ética e consentimento & $\begin{array}{l}\text { O estudo foi aprovado pelo Comitê de Ética em Pesquisa da } \\
\text { Universidade Federal de Pernambuco sob protocolo CAEE } \\
72115817.1 .0000 .5208\end{array}$ \\
\hline Financiamento & Não houve financiamento \\
\hline
\end{tabular}

